\title{
Construction of simplified design $p-y$ curves for liquefied soils
}

\author{
D. LOMBARDI*, S. R. DASH†, S. BHATTACHARYA
}

\begin{abstract}
In practice, laterally loaded piles are most often analysed using a 'beam-on-non-linear-Winklerfoundation' approach, whereby the soil-structure interaction is modelled by means of $p-y$ curves. Although well-calibrated $p-y$ curves exist for non-liquefied soils (e.g. soft clay and sand), the profession still lacks reliable $p-y$ curves for liquefied soils. In fact, the latter should be consistent with the observed strain-stiffening behaviour exhibited by liquefied samples in both element and physical model tests. It is recognised that this behaviour is induced by the tendency of the liquefied soil to dilate upon undrained shearing, which ultimately results in a gradual decrease in excess pore pressure, and consequent increase in stiffness and strength. The aim of this paper is twofold. First, it proposes an easy-to-use empirical model for constructing stress-strain relationships for liquefied soils. This only requires three soil parameters which can conveniently be determined by means of laboratory tests. Second, it introduces a method for the construction of $p-y$ curves for liquefiable soils from the proposed stress-strain model, based on the scaling of stress and strain into compatible soil reaction $p$ and pile deflection $y$, respectively. The scaling factors for stress and strain are computed following an energy-based approach that is analogous to the upper-bound method used in classical plasticity theory. To validate the proposed $p-y$ curves, results from a series of centrifuge tests are employed to back-calculate $p-y$ curves for liquefied soils. The latter are compared with those obtained from the proposed method and the conventional $p$-multiplier approach.
\end{abstract}

KEYWORDS: centrifuge modelling; dynamics; laboratory tests; liquefaction; piles \& piling; soil/structure interaction

\section{INTRODUCTION}

Poor performance of pile foundations, ranging from cracks to formation of plastic hinges, is still observed in liquefiable soils after most major earthquakes. As a result, the behaviour of piled foundations during liquefaction remains an area of active research (Haigh, 2002; Bhattacharya, 2003; Bhattacharya et al., 2004, 2005a, 2005b; Cubrinovski et al., 2006; Knappett \& Madabhushi, 2009; Dash et al., 2010; Madabhushi et al., 2010; Stringer \& Madabhushi, 2012; Lombardi, 2013; Lombardi \& Bhattacharya, 2014a, 2016).

To model laterally loaded piles, practising engineers often use a simplified method normally referred to as 'beamon-non-linear-Winkler-foundation' (BNWF) (Winkler, 1867; Hetényi, 1946). This method stands on the hypothesis that the soil reaction exerted by the soil at a given depth on the pile shaft is proportional to the relative pile-soil lateral deflection. According to the BNWF method, the pile is modelled by means of consecutive beam-column elements, whereas the lateral pile-soil interaction is analysed through non-linear springs that are attached to nodal points between two consecutive elements. Each spring can be defined by means of a non-linear relationship between the soil reaction (per unit length of the pile), $p$, and the corresponding relative soil-pile horizontal displacement, $y$. The coefficient of proportionality between $p$ and $y$ is referred to as modulus of

Manuscript received 10 June 2015; revised manuscript accepted 30 August 2016. Published online ahead of print 25 October 2016. Discussion on this paper closes on 1 August 2017, for further details see p. ii.

Published with permission by the ICE under the CC-BY license. (http://creativecommons.org/licenses/by/4.0/)

* The University of Manchester, Manchester, UK.

$\dagger$ Indian Institute of Technology Bhubaneswar, Bhubaneswar, Odisha, India.

t University of Surrey, Guildford, UK.

$\S$ University of Bristol, Bristol, UK. subgrade reaction $k$, with dimension of pressure divided by length. This relationship is normally known as a $p-y$ curve, or reaction curve. Despite the limitation inherent to the discrete nature of the method, BNWF is extensively used in practice owing to its mathematical convenience and ability to incorporate non-linearity of the soil and ground stratification. The validity of the BNWF approach is based on the assumed similarity between two mechanical system responses: (a) the load-deformation response of the pile, which takes into account the overall macro behaviour of the soil-pile system; $(b)$ the stress-strain response of the adjacent soil being sheared as the pile moves laterally. The latter is related to the micro behaviour of the deforming material. In theory, the transformation from micro to macro can be made by applying appropriate scaling factors, whereby stress is converted into equivalent soil reaction, $p$; and strain is converted into equivalent relative pile-soil displacement, $y$. Bouzid et al. (2013) concluded that these scaling factors can be derived from the so-called 'mobilisable strength design' (MSD) method (Bolton \& Powrie, 1988; Osman \& Bolton, 2004; Vardanega \& Bolton, 2011). In routine practice, however, $p-y$ curves are constructed by means of empirical relationships, which were developed in the 1970s to 1980 s based on a relatively limited number of full-scale tests carried out on small-diameter steel piles (Matlock, 1970; Reese et al., 1974, 1975; O’Neill \& Murchison, 1983).

One of the first methods to construct $p-y$ curves for liquefiable soils was given by Dobry et al. (1995). The method, qualitatively illustrated in Fig. 1, consists of applying to the conventional $p-y$ curve for non-liquefied sand a reduction factor $m_{\mathrm{p}}$. The latter can be conveniently determined from the equivalent clean sand blow count, $\left(N_{1}\right)_{60}$, using empirical charts, such as the one depicted in Fig. 1(b). An alternative method is to use $p-y$ curves for soft clays, for example the ones recommended by API (2000), but replacing the undrained shear strength of the clay by the residual strength of the liquefied soil, $S_{\mathrm{r}}$ (Goh \& O'Rourke, 1999). 


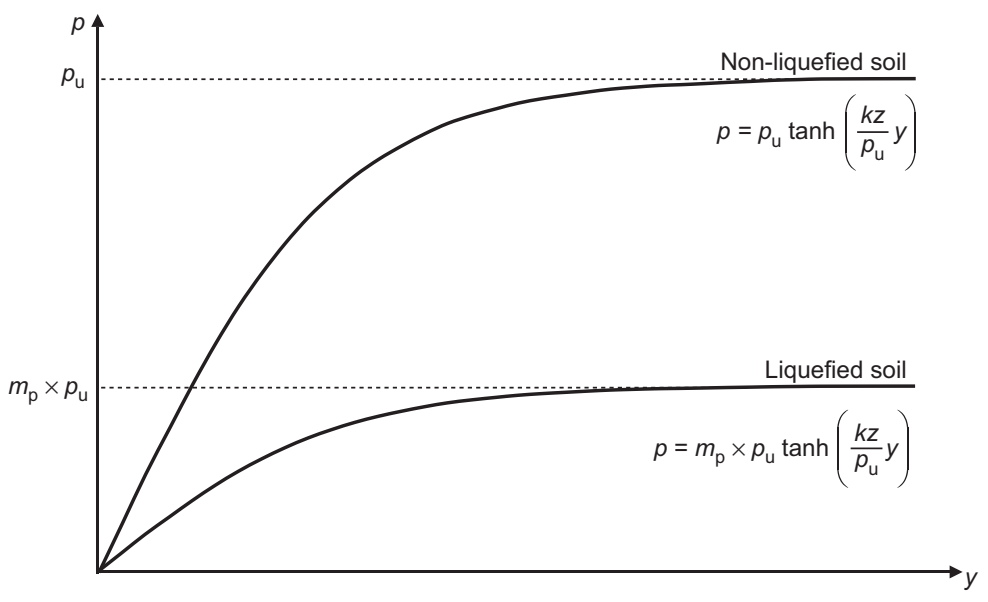

(a)

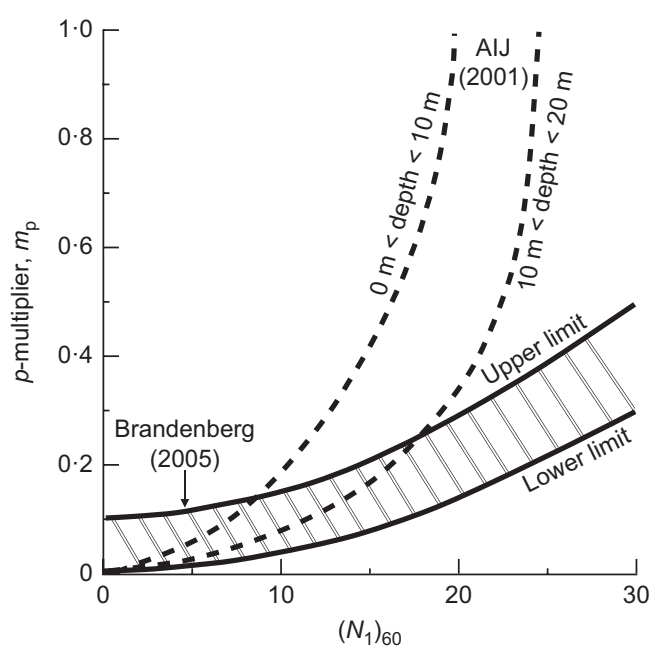

(b)

Fig. 1. Construction of $p-y$ curves for liquefiable soils according to $p$-multiplier approach: (a) application of degradation factor $m_{\mathrm{p}}$ to $p-y$ curves for non-liquefied sands prescribed by API (2000); (b) degradation factor $m_{p}$ plotted against equivalent clean sand blow count from standard penetration test (SPT) $\left(N_{1}\right)_{60}$ (after AIJ, 2001; Brandenberg, 2005)

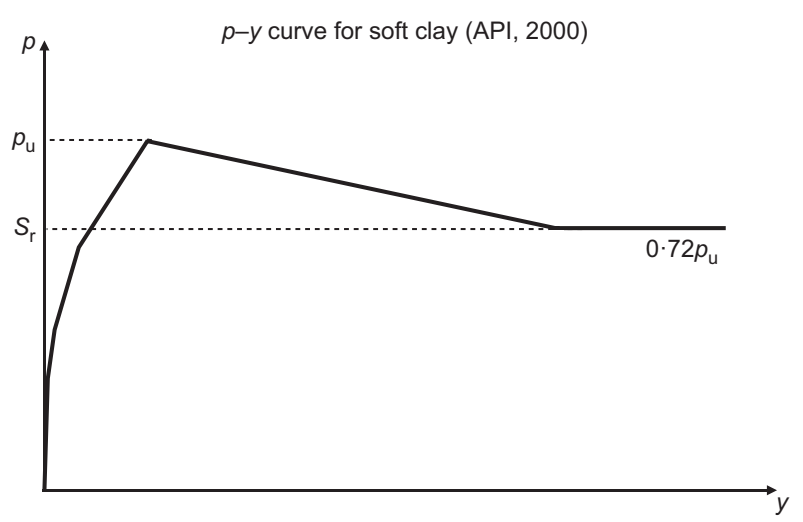

(a)

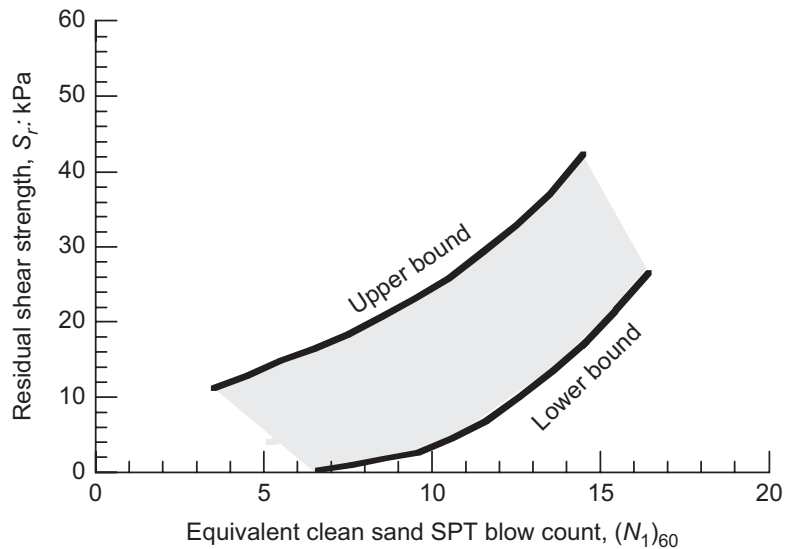

(b)

Fig. 2. Construction of $p-y$ curves for liquefiable soils according to residual strength approach: (a) schematic $p-y$ curves for soft clays

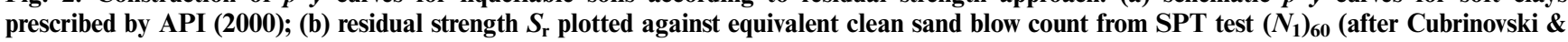
Bradley, 2008)

This approach is normally referred to as residual strength approach and is schematically illustrated in Fig. 2. The residual strength of the liquefied soil can be estimated from empirical charts (see Fig. 2(b)) proposed by several researchers (Seed \& Harder, 1990; Pillai \& Salgado, 1994; Olson \& Stark, 2002; Brandenberg, 2005).

It can be concluded that, in routine practice, $p-y$ curves for liquefied soils exhibit a strain-softening behaviour, characterised by a relatively high stiffness at small displacements that gradually reduces upon shearing. This response, however, is substantially different from the strain-stiffening behaviour observed in both element and physical model tests. In fact, a number of studies (Wilson et al., 2000; Tokimatsu et al., 2001; Ashford \& Rollins, 2002; Boulanger et al., 2003) have shown that back-calculated $p-y$ curves of liquefied soils have a concave upward shape (see Fig. 3(b)), characterised by practically zero stiffness at small displacements, but increasing stiffness and strength upon shearing. It is worth noting that this strain-stiffening response - hereafter referred to as strain-hardening - is consistent with the post-liquefaction behaviour of sands observed in element tests by several researchers (Yasuda et al., 1994; Vaid \& Thomas, 1995;

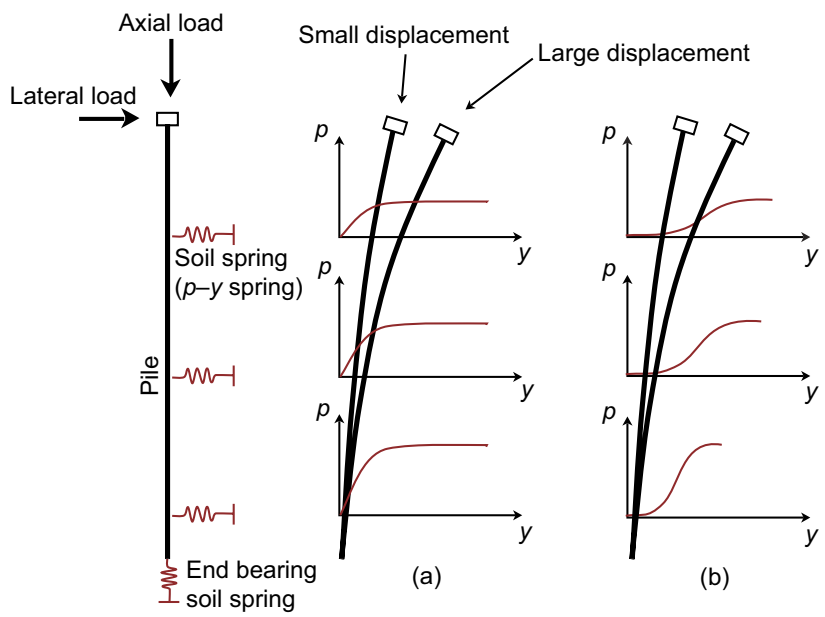

Fig. 3. Effect of shape of $p-y$ curve on the mobilised strength and stiffness of a pile foundation in a liquefied layer (solid lines schematically indicate the deflected shape of the pile at small and large displacement): (a) $p-y$ curves from $p$-multiplier approach; (b) proposed strain-hardening $p-y$ curves 
Sivathayalan \& Vaid, 2004; Sitharam et al., 2009; Dash, 2010; Lombardi et al., 2014).

Figure 3 illustrates the effect of different shapes of $p-y$ curves on the seismic response of piled foundations. Starting from the concave-downward $p-y$ curve illustrated in Fig. 3(a), it can be noted that when the lateral displacement is relatively small, the soil-pile interaction depends on the initial stiffness of the reaction curve. For large displacement, however, the response is influenced by the ultimate value of the soil reaction rather than foundation stiffness. On the other hand, if the shape of the $p-y$ curve is concave-upward, as in Fig. 3(b), the response of the pile is highly non-linear and exhibits practically zero stiffness at small displacements. Moreover, as a result of the limited resistance offered by the liquefied soil, the pile behaves as an unsupported column, which may be prone to buckling instability under large axial loads and the presence of geometrical imperfections.

The motivation behind this research is to formulate a simplified $p-y$ curve for the analysis of soil-structure interaction problems in liquefied soils. The proposed curves can be constructed from a simplified stress-strain model that requires only three parameters. These are hereafter referred to as: take-off strain $\gamma_{\text {to }}$, initial shear modulus, $G_{1}$ and shear modulus at large strains, $G_{2}$. The advantage of this model is twofold. First, the proposed stress-strain model requires parameters that can be conveniently determined by means of conventional element tests, such as triaxial and simple shear tests. Second, the stress-strain relationship is consistent with the strain-hardening behaviour of liquefied soils as observed in both element and physical model tests. The proposed stress-strain relationships are subsequently used to construct a novel family of $p-y$ curves for liquefiable soils. This involves scaling of stress and strain into compatible soil reaction $p$ and pile deflection $y$, respectively. The proposed $p-y$ curves are finally compared with those back-calculated from centrifuge model tests.

\section{POST-LIQUEFACTION STRESS-STRAIN RESPONSE}

Only a limited number of studies have focused on the post-liquefaction behaviour of liquefied soils. A pioneering work by Seed (1979) focused on the post-earthquake stability of dams in liquefiable deposits and concluded that liquefied soils gradually mobilised increasing strength and stiffness upon shearing. This strain-hardening behaviour was confirmed in subsequent studies by Yoshida et al. (1994) and Kiku \& Tsujino (1996). Thomas (1992) and Vaid \& Thomas (1995) showed that the post-liquefaction behaviour of sands subjected to undrained monotonic loading was dilative, even if the sand showed contractive and strain-softening behaviour before the onset of liquefaction. This observation was later confirmed by Sivathayalan \& Vaid (2004), who carried out tests on in situ frozen samples of alluvial sands. It was found that the post-liquefaction behaviour exhibited a strainhardening response owing to the tendency of the liquefied soil to dilate upon shearing. Yasuda et al. (1994) observed that the initiation of dilative behaviour occurred beyond a threshold strain. This was found to be strongly dependent on the initial relative density of the sand, whereby denser sands mobilised higher strength at smaller strains. Kokusho et al. (2004) investigated the effect of different particle gradations on the post-liquefaction undrained behaviour of sands. It was found that in well-graded soils the tendency to dilate was more pronounced than that exhibited by poorly graded soils. A recent study by Sitharam et al. (2009) showed that the monotonic behaviour of liquefied soil was affected by the amplitude of the cyclic axial strain applied to cause liquefaction. On the other hand the post-liquefaction behaviour was found to be independent of the confining stress. Dash (2010)

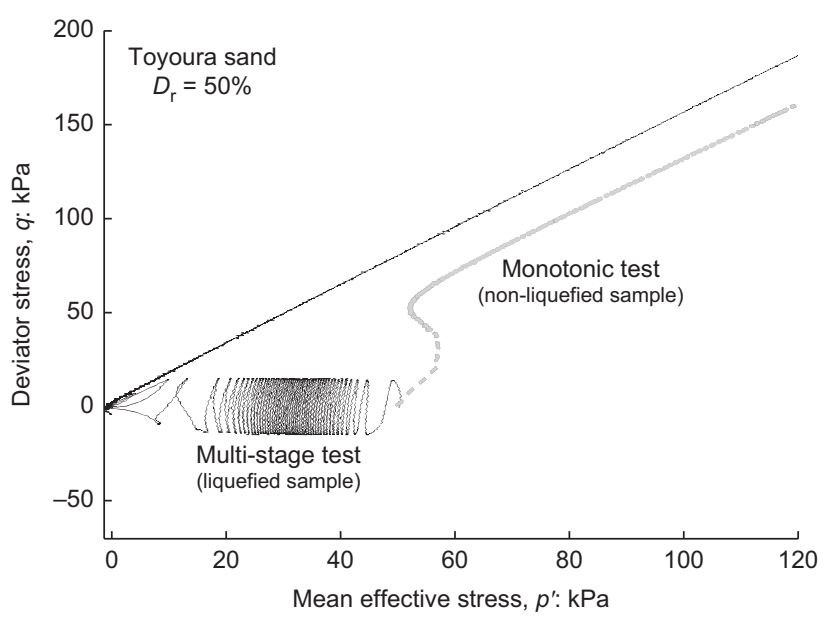

(a)

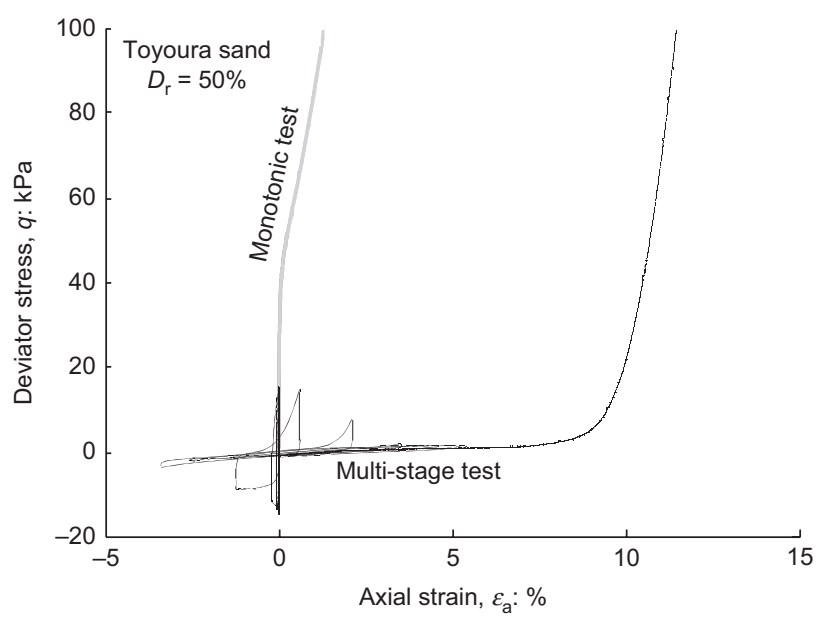

(b)

Fig. 4. Undrained behaviour of Toyoura sand subjected to different loading paths, namely monotonic load (in grey), multi-stage load (in black): (a) effective stress path; (b) stress-strain response (after Dash, 2010)

compared the undrained monotonic behaviour of liquefied and non-liquefied samples whose responses are shown in Fig. 4. More specifically, the figure shows results for two samples of Toyoura sand with the same initial relative density $\left(D_{\mathrm{r}}=50 \%\right)$, consolidated at the same effective stress $\left(\sigma_{\mathrm{c}}^{\prime}=50 \mathrm{kPa}\right)$, but subjected to different loading paths, namely monotonic load and multi-stage load. It is noted that the multi-stage test consisted of two undrained loading stages, whereby the sample was initially liquefied by means of cyclic load and subsequently sheared monotonically, with no drainage permitted between the two stages. In Fig. 4(a), it can be seen that the effective stress path initially moved towards the origin of axes, owing to the gradual increase in excess pore pressure, and consequent reduction in $p^{\prime}$, until it generated the characteristic 'butterfly' shape shown in Fig. 4(a). After the onset of liquefaction, the stress path moved towards the direction of increasing $p^{\prime}$ owing to the progressive reduction in excess pore pressure due to the tendency of the liquefied soil to dilate upon shearing. It is worth noting that, at large strains, the slopes of the effective stress paths obtained from the two samples were practically identical. Figure 4(b) compares the stress-strain response obtained from the two tests. It can be seen that the sample subjected to the multi-stage test initially displayed a stressstrain loop that gradually enlarged with the application of cycles of loading. In the post-cyclic monotonic stage, the 
liquefied sample exhibited a very low stiffness at small strains, which gradually increased upon shearing. It was found that the liquefied and non-liquefied samples mobilised a comparable stiffness at large strains.

\section{PROPOSED MONOTONIC POST-LIQUEFACTION STRESS-STRAIN CURVE}

With the current understanding of the behaviour of liquefied samples, and its influencing factors, a simplified monotonic post-liquefaction stress-strain model is herein proposed. The aim is to provide practitioners with a stressstrain curve for liquefied soil. As illustrated in Fig. 5, the proposed model requires the following parameters.

(a) Take-off shear strain $\gamma_{\text {to }}$ : engineering shear strain upon which the shear strength of the liquefied soil exceeds $1 \mathrm{kPa}$ upon monotonic undrained shearing. The observed stress-strain response (see Fig. 4), shows that the transition between $G_{1}$ and $G_{2}$ is quite smooth and may occur over $1-2 \%$ of shear strain. In order to make some allowance for this transition, the proposed value of $\gamma_{\text {to }}$ is increased by $25 \%$. As a result, the second linear segment of the stress-strain model starts from $1 \cdot 25 \gamma_{\text {to. }}$.

(b) Initial shear modulus $G_{1}$ : shear modulus exhibited by the liquefied soil at strains $\gamma<\gamma_{\text {to }}$.

(c) Shear modulus at large strains $G_{2}$ : tangent shear modulus exhibited by the liquefied soil sheared at strains $\gamma>\gamma_{\text {to. }}$.

(d) Maximum shear stress $\tau_{\max }$ : maximum shear stress mobilised by the liquefied soil at very large strains $\gamma>>\gamma_{\text {to }}$.

It should be pointed out that only the first three parameters, namely, $\gamma_{\text {to }}, G_{1}$ and $G_{2}$, can be obtained from laboratory tests. However, the maximum shear stress, $\tau_{\max }$, is only required because the test conditions are not fully representative of those established in the field. In fact, triaxial tests are typically performed with the application of a back pressure in order to improve sample saturation. Samples that

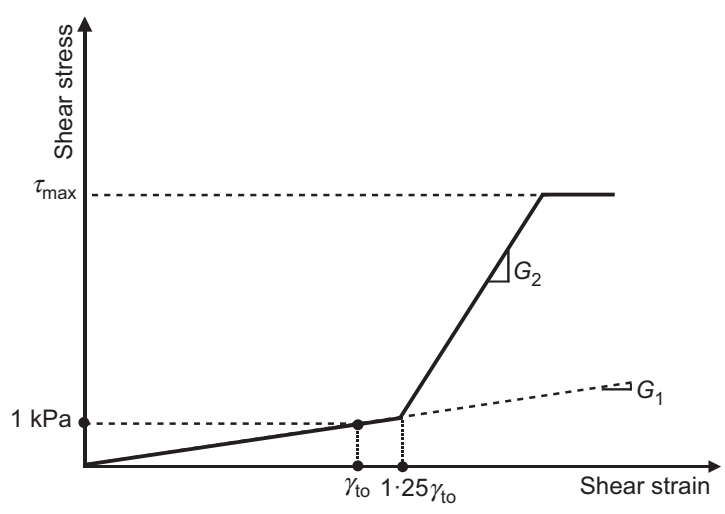

Fig. 5. Proposed (monotonic) stress-strain curve for liquefied soil exhibit a tendency to dilate - as they are sheared under undrained condition - tend to generate negative pore pressures. While the pore pressure is becoming increasingly negative, the effective mean effective stress becomes increasingly positive and the strength increases. The back pressure provides some guard against the pore pressure actually falling to zero. However, continued suppressed dilation may eventually lead to a pore pressure below $-100 \mathrm{kPa}$, at which point the pore water will cavitate and 'boil'. The generation of gas in the pore water would turn the undrained test into a drained test. The potential to mobilise such high negative pressures is not usually present in situ; therefore the fourth parameter represents a capped shear stress to take into account the actual soil behaviour in the field.

\section{EVALUATION OF PARAMETERS $\gamma_{\mathrm{to}}, G_{1}$ AND $G_{2}$}

The advantage of the proposed stress-strain model for liquefied soils lies in its simplicity and ease of implementation. In fact, the empirical parameters, that is, $\gamma_{\text {to }}, G_{1}$ and $G_{2}$, can conveniently be determined by performing multistage laboratory tests, whereby the sample is initially liquefied by means of cyclic loading, and subsequently sheared in undrained monotonic condition without dissipation of excess pore pressure between the two stages. In the absence of adequate facilities (e.g. cyclic triaxial, cyclic simple shear and so on), and for preliminary design considerations, the three parameters can be estimated from data available in the literature. In this paper, the three parameters have been determined from published test results obtained from samples of sands whose index properties are listed in Table 1. Fig. 6 shows the particle distributions of these sands, conjointly with grain size distributions of liquefaction-prone soils. A summary of test data is listed in Table 2.

\section{Take-off shear strain, $\gamma_{t o}$ and initial shear modulus, $\mathrm{G}_{I}$}

The take-off shear strain, $\gamma_{\text {to }}$, defined as the engineering shear strain required to mobilise a shear strength of $1 \mathrm{kPa}$, is determined from the stress-strain response of liquefied samples subjected to undrained monotonic loading, which have been previously liquefied by the application of cyclic loads (see for example test in Fig. 4(b)). In the interpretation of the collated data, the deviator stress $q$ and axial strain $\varepsilon_{\mathrm{a}}$ from triaxial tests have been converted into equivalent shear stress $\tau=q / 2$ and engineering shear strain, $\gamma=1 \cdot 5 \varepsilon_{\mathrm{a}}$, respectively. Fig. 7(a) plots the computed $\gamma_{\text {to }}$ against initial relative density $D_{\mathrm{r}}$. Beyond the observed scatter, it appears that the take-off shear strain decreases with increasing $D_{\mathrm{r}}$. Following the definition of take-off strain, the initial shear modulus can be estimated by $G_{1}=1 / \gamma_{\text {to }}$, where $G_{1}$ is in kPa. Fig. 7(b) displays the computed $G_{1}$ plotted against initial relative density $D_{\mathrm{r}}$. It can be observed that the initial stiffness increases exponentially with increasing $D_{\mathrm{r}}$.

Table 1. Index properties of sands considered in this study

\begin{tabular}{l|c|c|c|c|c|l|l}
\hline Sand & $G_{\mathrm{s}}$ & $e_{\max }$ & $e_{\min }$ & $D_{50}: \mathrm{mm}$ & $U_{\mathrm{c}}$ & Particle shape & Reference \\
\hline Redhill 110 & $2 \cdot 65$ & $1 \cdot 04$ & $0 \cdot 61$ & $0 \cdot 14$ & $1 \cdot 63$ & Angular & Lombardi et al. (2014) \\
Toyoura & $2 \cdot 64$ & $0 \cdot 97$ & $0 \cdot 64$ & $0 \cdot 18$ & $1 \cdot 66$ & Sub-angular & Lombardi et al. (2014) \\
Fraser river & $2 \cdot 72$ & $1 \cdot 00$ & $0 \cdot 68$ & $0 \cdot 30$ & $1 \cdot 68$ & Sub-angular to sub-rounded & Vaid \& Thomas (1995) \\
Syncrude & $2 \cdot 62$ & $0 \cdot 96$ & $0 \cdot 55$ & $0 \cdot 20$ & $3 \cdot 34$ & Angular to sub-angular & Sivathayalan (1994) \\
Narita & $2 \cdot 70$ & $1 \cdot 37$ & $0 \cdot 77$ & $0 \cdot 12$ & $3 \cdot 08$ & Angular to sub-angular & Yasuda et al. (1994) \\
\hline
\end{tabular}

Note: $G_{\mathrm{s}}$, specific gravity; $e_{\max }, e_{\min }$, maximum and minimum void ratio; $D_{50}, 50 \%$ finer size; $U_{\mathrm{c}}$, coefficient of uniformity. 
Shear modulus at large strains, $\mathrm{G}_{2}$

As shown in Fig. 4(b), the shear modulus of the liquefied sample is practically constant for shear strains larger than $\gamma_{\text {to }}$. The shear modulus at large strain may be derived from theoretical considerations that should take into account the effect of the rate of dilation and level of confinement. Such an approach, however, would involve a rather laborious mathematical derivation that seems excessive for the present initial simplified analysis. Looking for alternative correlations that may exist between $G_{2}$ and any other soil parameters, it is herein proposed to estimate the $G_{2}$ based on the ratio $G_{2} / G_{\max }$, where $G_{\max }$ denotes the tangent shear modulus at small strains, that is, $<10^{-6}$ (Kramer, 1996). According to Ishihara (1995), $G_{\max }$ can be estimated from the initial void ratio of the sample, $e$, and confining stress, $\sigma_{\mathrm{c}}^{\prime}$, according to equation (1). Fig. 8 plots $G_{2} / G_{\max }$ against $D_{\mathrm{r}}$ for the collated data.

$$
G_{\max }=8400 \frac{(2 \cdot 17-e)^{2}}{(1+e)}\left(\sigma_{\mathrm{c}}^{\prime}\right)^{0.5} \quad\left(\sigma_{\mathrm{c}}^{\prime} \text { and } G_{\max } \text { in } \mathrm{kPa}\right)
$$

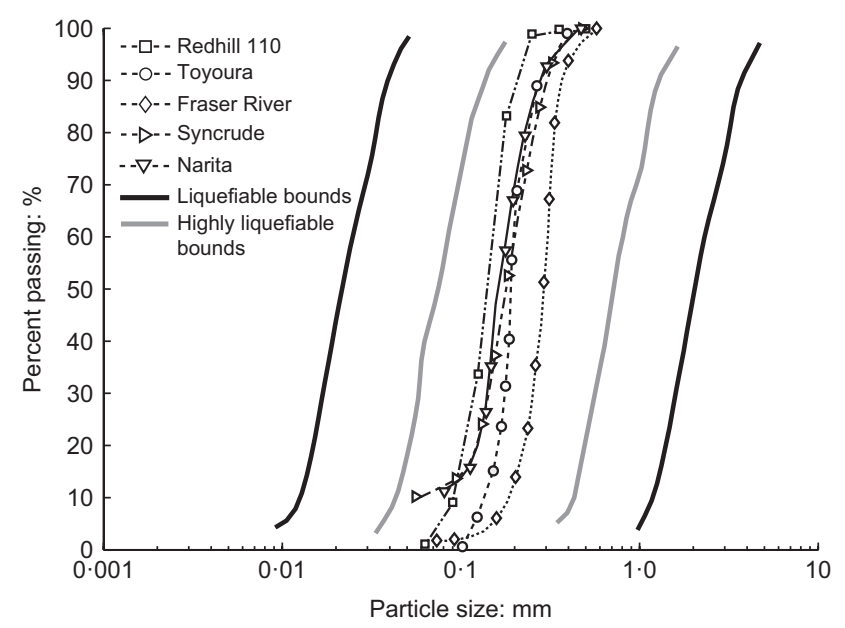

Fig. 6. Grain size distributions of sands considered in this work for the evaluation of $\gamma_{\text {to }}, G_{1}$ and $G_{2}$, and grading bounds for highly liquefiable and liquefiable sands according to the Japanese seismic code for harbour structures
Figure 8 shows that the computed data are randomly scattered, presumably due to variations in excess pore pressure between samples prepared at different relative densities. The figure, however, identifies three different ranges of $G_{2} / G_{\max }$, namely: $0 \cdot 1,0 \cdot 01$ and $0 \cdot 001$, which broadly depend on the degree of packing of the sample. Considering that $G_{2}$ is inversely proportional to confining stress, $\sigma_{\mathrm{c}}^{\prime}$, and directly proportional to $G_{\max }$, it is suggested to compute $G_{2}$ by using the expression suggested by Dash (2010), given by

$$
G_{2}=\frac{1}{5} \frac{G_{\max }}{\sqrt{\sigma_{\mathrm{c}}^{\prime}}}(\text { in } \mathrm{kPa})
$$

It is worth noting that equation (2) is based on the fitting of limited experimental data; however, this is consistent with the expression recommended by Ishibashi \& Zhang (1993).

\section{Maximum shear stress, $\tau_{\max }$}

The proposed stress-strain model for liquefied soils depicted in Fig. 5 implies that the increase in shear stress cannot continue indefinitely upon shearing because the dilatative behaviour exhibited by the liquefied soil terminates at large strains. From a theoretical point of view, the maximum shear is attained when the pore pressure reaches a negative value equal to $-100 \mathrm{kPa}$, upon which cavitation of the pore water occurs in the sample. According to this reasoning, the limiting value of shear stress can be computed as follows

$$
\tau_{\max }=\frac{q_{\max }}{2}=\frac{M_{\mathrm{c}}\left(\sigma_{\mathrm{c}}^{\prime}+p_{\mathrm{a}} \mathrm{kPa}\right)}{2}
$$

in which $M_{\mathrm{c}}$ denotes the stress ratio at critical state under conditions of triaxial compression, and $p_{\mathrm{a}}$ is the atmospheric pressure.

An alternative approach would consist in equating $\tau_{\max }$ to the residual strength $S_{\mathrm{r}}$ of the liquefied soil. The latter can conveniently be estimated based on empirical correlations, such as the ones given in Fig. 2(b).

\section{CONSTRUCTION OF $p-y$ CURVES FROM STRESS-STRAIN CURVE OF LIQUEFIED SOILS}

The proposed method for the construction of $p-y$ curves

\begin{tabular}{|c|c|c|c|c|c|}
\hline Material & $D_{\mathrm{r}}: \%$ & $\sigma_{\mathrm{c}}^{\prime}: \mathrm{kPa}$ & Apparatus & Monotonic strain rate & Reference \\
\hline Toyoura & 23 & 50 & Cyclic torsional shear & $10 \% /$ min & Yasuda et al. (1994) \\
\hline Toyoura & 30 & 50 & Cyclic torsional shear & $10 \% / \mathrm{min}$ & Yoshida et al., 1994 \\
\hline Toyoura & 33 & 50 & Cyclic torsional shear & $10 \% / \mathrm{min}$ & Yasuda et al. (1994) \\
\hline Toyoura & 38 & 50 & Cyclic triaxial & $1 \% / \min$ & Lombardi et al. (2014) \\
\hline Toyoura & 44 & 100 & Cyclic triaxial & $1 \% / \min$ & Lombardi et al. (2014) \\
\hline Toyoura & 50 & 98 & Cyclic torsional shear & $10 \% / \mathrm{min}$ & Yasuda et al. (1998) \\
\hline Toyoura & 70 & 50 & Cyclic triaxial & $10 \% / \mathrm{min}$ & Yoshida et al. (1994) \\
\hline Redhill 110 & 33 & 100 & Cyclic triaxial & $1 \% / \min$ & Lombardi et al. (2014) \\
\hline Redhill 110 & 37 & 100 & Cyclic triaxial & $1 \% /$ min & Lombardi et al. (2014) \\
\hline Redhill 110 & 40 & 50 & Cyclic triaxial & $1 \% / \min$ & Lombardi et al. (2014) \\
\hline Redhill 110 & 48 & 100 & Cyclic triaxial & $1 \% /$ min & Lombardi et al. (2014) \\
\hline Redhill 110 & 59 & 100 & Cyclic triaxial & $1 \% / \min$ & Lombardi et al. (2014) \\
\hline Redhill 110 & 67 & 110 & Cyclic triaxial & $1 \% / \min$ & Lombardi et al. (2014) \\
\hline Fraser River & 19 & 100 & Cyclic triaxial & $1 \% / \min$ & Vaid \& Thomas (1995) \\
\hline Fraser River & 28 & 100 & Cyclic simple shear & $1 \% / \min$ & Sivathayalan (1994) \\
\hline Fraser River & 39 & 100 & Cyclic simple shear & $1 \% / \min$ & Sivathayalan (1994) \\
\hline Fraser River & 60 & 100 & Cyclic simple shear & $1 \% / \min$ & Sivathayalan (1994) \\
\hline Syncrude & 51 & 100 & Cyclic simple shear & $1 \% / \mathrm{min}$ & Sivathayalan (1994) \\
\hline Narita & 38 & 50 & Cyclic torsional shear & $10 \% / \min$ & Yasuda et al. (1994) \\
\hline Narita & 53 & 50 & Cyclic torsional shear & $10 \% / \mathrm{min}$ & Yasuda et al. (1994) \\
\hline
\end{tabular}
from stress-strain curves relies on the similarity between

Table 2. Test data used for derivation of parameters $\gamma_{\text {to }}, G_{1}$ and $G_{2}$ 


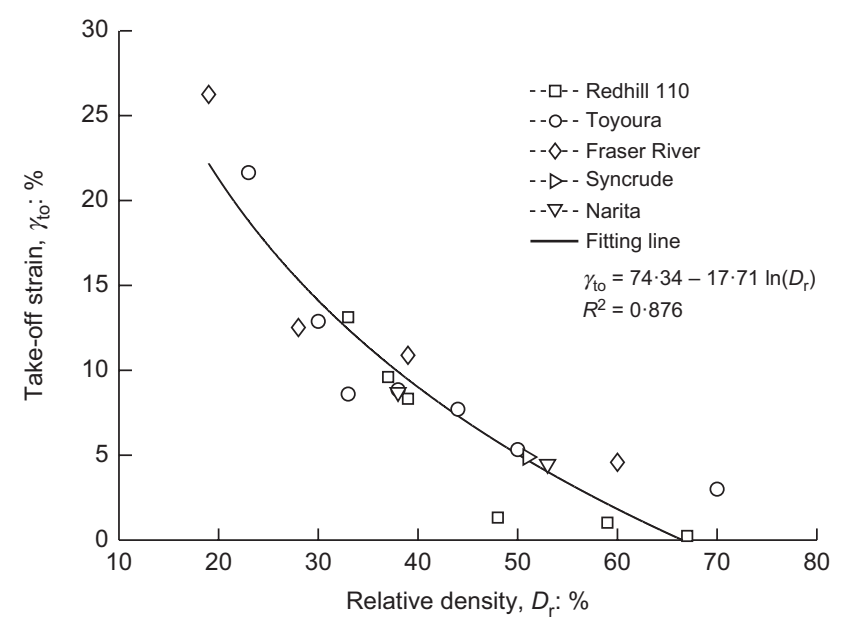

(a)

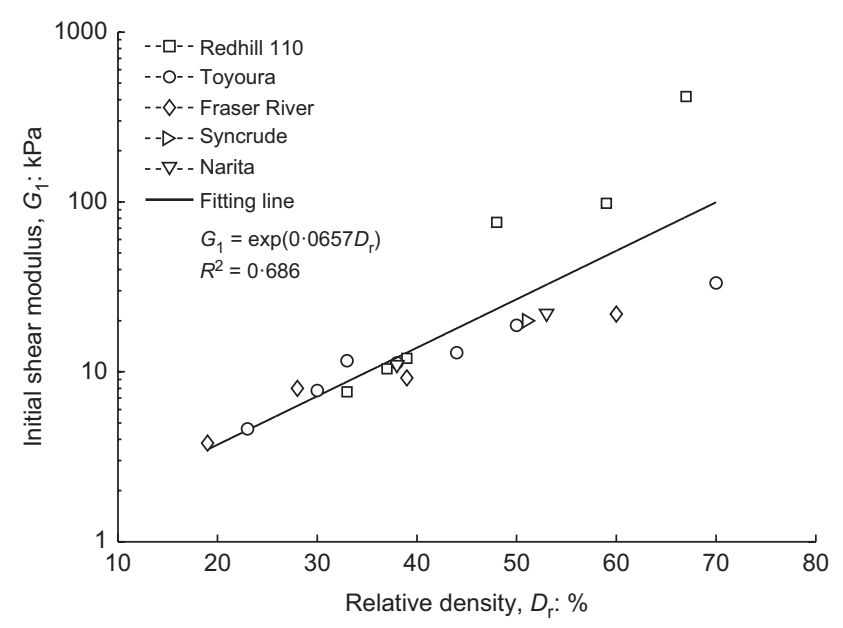

(b)

Fig. 7. Estimated parameters for proposed stress-strain curve: (a) take-off strain $\gamma_{\text {to }}$ plotted against initial relative density $D_{\mathrm{r}}$; (b) initial shear modulus of liquefied soil $G_{1}$ plotted against initial relative density $D_{\mathrm{r}}$

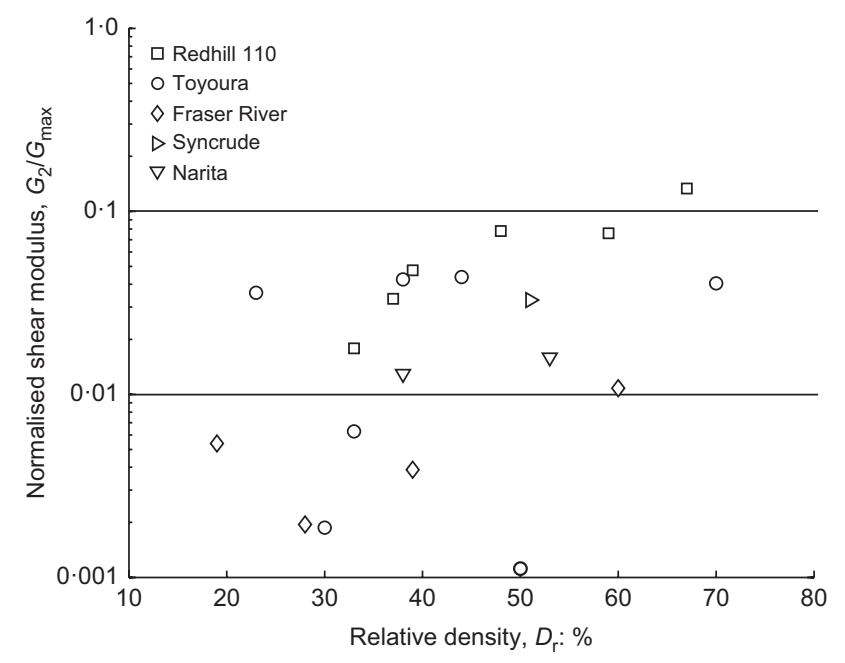

Fig. 8. Shear modulus of liquefied soil at large strains, normalised by maximum shear modulus, $G_{2} / G_{\max }$ plotted against initial relative density $D_{\mathbf{r}}$

load-deflection characteristics of the pile and mechanical behaviour of the deforming soil. This involves scaling of stress and strain into compatible soil reaction, $p$, and pile deflection, $y$, respectively. It is assumed that plane strain

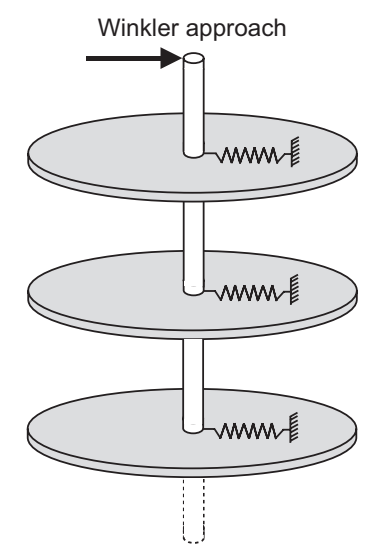

(a)

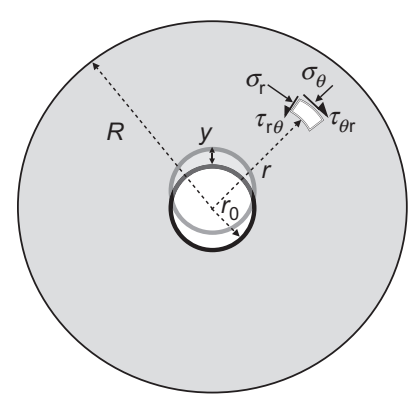

(b)
Fig. 9. Schematic representation of idealised decoupled plane strain problem for studying soil-structure interaction: (a) modelling of laterally loaded pile according to Winkler approach; (b) plane strain problem at a given depth

conditions are established around the pile at any depth. As a result, soil adjacent the foundation is expected to flow around the pile from front to back. Although such an assumption is acceptable for liquefied soils, the same may not be valid prior to the onset of liquefaction, when wedge-type failure is likely to occur, particularly at shallow depths. In accordance with the postulated collapse mechanism, the soil-structure interaction problem can be treated as a set of decoupled plane strain problems. As shown in Fig. 9, each problem consists of a disc representing the soil, with outer radius $R$, and a smaller rigid disc, with outer radius $r_{0}$, which represents the pile moving laterally in the deforming soil. The soil is assumed to adhere perfectly to the pile. It should be emphasised that the conceptualised problem is analogous to the plane strain problem employed in plasticity theory for the evaluation of the undrained lateral capacity of a cylinder moving through an infinite medium (Randolph \& Houlsby, 1984).

Following Osman \& Bolton (2005) and Klar (2008), the soil resistance, $p$, developed at a mobilised stress, $\tau_{\text {mob }}$, is given by

$$
p=N_{\mathrm{s}} \tau_{\mathrm{mob}} D
$$

in which $N_{\mathrm{s}}$ is a scaling factor for stress. The mobilised shear stress, $\tau_{\mathrm{mob}}$, can be related to an average mobilised engineer-

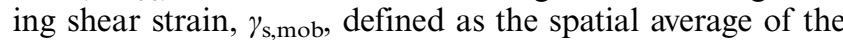
shear strain $\gamma_{\mathrm{s}}$ in the entire volume of the deforming medium. Introducing the scaling factor for strain, $M_{\mathrm{s}}$, the average mobilised engineering shear strain is given by

$$
\gamma_{\mathrm{s}, \mathrm{mob}}=\frac{\int_{V} \gamma_{\mathrm{s}} \mathrm{d} V}{\int_{V} \mathrm{~d} V}=M_{\mathrm{s}} \frac{y}{D}
$$

It is noted that the engineering shear strain, $\gamma_{\mathrm{s}}$, is defined as the difference between major $\varepsilon_{1}$ and minor $\varepsilon_{3}$ principal strains

$$
\gamma_{\mathrm{s}}=\varepsilon_{1}-\varepsilon_{3}
$$

If the stress-strain curve to be converted into a $p-y$ curve is obtained from triaxial compression tests, the major and minor principal strains correspond to the axial $\varepsilon_{\mathrm{a}}$ and radial $\varepsilon_{\mathrm{r}}$ strains, respectively. Considering that liquefaction occurs in undrained condition, the engineering shear strain, $\gamma_{\text {s }}$, can be expressed in terms of axial strain, $\varepsilon_{\mathrm{a}}$, such that

$$
\gamma_{\mathrm{s}}=\varepsilon_{1}-\varepsilon_{3}=\varepsilon_{\mathrm{a}}-\varepsilon_{\mathrm{r}}=1 \cdot 5 \varepsilon_{\mathrm{a}}
$$

Considering that in the triaxial apparatus the loading is axisymmetric, and neglecting end-effects and possible 
problems associated with initial anisotropy of the sample, the major $\sigma_{1}$ and minor $\sigma_{3}$ principal stresses correspond to the axial $\sigma_{\mathrm{a}}$ and radial $\sigma_{\mathrm{r}}$ stresses, respectively. In this condition the mobilised stress, $\tau_{\text {mob }}$, simplifies to

$$
\tau_{\mathrm{mob}}=\frac{\sigma_{1}-\sigma_{3}}{2}=\frac{\sigma_{\mathrm{a}}-\sigma_{\mathrm{r}}}{2}
$$

\section{Derivation of scaling parameters}

Drawing on the concept of the MSD method (Bolton \& Powrie, 1988; Osman \& Bolton, 2005), and its extension (EMSD) by Klar \& Osman (2008), which differs from the former in having a deformation mechanism that changes throughout the loading sequence, an energy-based approach is used to obtain the scaling factors $N_{\mathrm{s}}$ and $M_{\mathrm{s}}$. Assuming that the soil-pile system is initially in equilibrium, the rate of input work $\dot{W}$ done by the moving disc - representing the pile - is given by

$$
\dot{W}=p \dot{y}
$$

in which $\dot{y}$ denotes the increment in lateral displacement, and $p$ the resulting soil reaction (per unit length of the pile).

The rate of dissipation of energy $\dot{E}$ within the deforming soil mass, with volume $V$, is given by

$$
\dot{E}=\int_{V}\left(\sigma_{1} \dot{\varepsilon}_{1}+2 \sigma_{3} \dot{\varepsilon}_{3}\right) \mathrm{d} V
$$

The hypothesis of incompressibility implies that major and minor principal strain rates are equal and opposite $\dot{\varepsilon}_{1}=-\dot{\varepsilon}_{3}$. Equation (9) can therefore be rearranged such that the rate of dissipation of energy, $\dot{E}$, is expressed as a function of mobilised parameters by

$$
\begin{aligned}
\dot{E} & =\int_{V}\left(\sigma_{1}-\sigma_{3}\right) \dot{\varepsilon}_{1} \mathrm{~d} V=2 \int_{V} \tau_{\mathrm{mob}} \dot{\varepsilon}_{1} \mathrm{~d} V \\
& =\int_{V} \tau_{\mathrm{mob}} \dot{\gamma}_{\mathrm{s}, \mathrm{mob}} \mathrm{d} V
\end{aligned}
$$

The scaling factor for stress $N_{\mathrm{s}}$ is estimated by equating the rate of dissipation of internal energy within the deforming soil to the work done by the externa load, namely, $\dot{E}=\dot{W}$. In seeking an upper-bound solution to the problem, $N_{\mathrm{s}}$ is sought, which minimises the internal work

$$
N_{\mathrm{s}}=\frac{\min \left[\int_{V} \tau_{\mathrm{mob}} \dot{\gamma}_{\mathrm{s}, \mathrm{mob}} \mathrm{d} V\right]}{\tau_{\mathrm{mob}} D \dot{y}}
$$

The upper-bound calculation required an incremental numerical procedure. In this study this was implemented in the finite-element code Comsol Multiphysics (Comsol, 2009). The soil was modelled using a triangular mesh, with Lagrange-quadratic elements (see Fig. 10(a)). A non-slip boundary was considered for the soil-pile interface, which corresponds to a rough surface. The incremental displacement $\dot{y}$ was applied to the inner boundary of the soil, whereas the exterior boundary was fixed (see Fig. 10). The deforming medium was modelled using the simplified strain-hardening model proposed by the authors (see Figs 5 and 11(a)). Specifically, six stress-strain curves were chosen for this parametric analysis, in which $\gamma_{\text {to }}, G_{1}$ and $\tau_{\max }$ were fixed, but the ratio $G_{2} / G_{1}$ was varied from 10 to 500 . The optimal upper-bound solution required the evaluation of the lowest possible value of $\dot{E}$, at each incremental displacement and different radial distances, $R$. The proposed scaling procedure of stress-strain into compatible $p-y$ curves is schematically depicted in Fig. 11(a).

Results obtained from the numerical analysis are plotted in Fig. 11(b). It can be seen that computed values of scaling factors were a function of $G_{2} / G_{1}$. Specifically, $N_{\mathrm{s}}$ ranged from $20 \cdot 23$ to $21 \cdot 3$, before attaining a practically constant value at large $G_{2} / G_{1}$. On the other hand, the scaling parameter for strain $M_{\mathrm{s}}$ decreased from 2.41 to 1.71 with increasing $G_{2} / G_{1}$. For design considerations, the lowest values of $N_{\mathrm{s}}$ and $M_{\mathrm{s}}$ can be considered as conservative. Therefore, the bearing capacity factor derived from classical theory of plasticity can be used for scaling stress into compatible soil reaction. According to Martin \& Randolph (2006), the bearing capacity factor $N_{\mathrm{s}}$ is $9 \cdot 2$ for a smooth pile-soil interface and 11.94 for a rough pile-soil interface.

Figure 11(b) shows that the scaling factor $M_{\mathrm{s}}$ is a non-linear function of $G_{2} / G_{1}$. For practical applications, however, scaling of strain into compatible deflection can be considered independent of $G_{2} / G_{1}$. As a result, $M_{\mathrm{s}}$ can be conservatively taken as the lowest value in Fig. 11(b), that is, $1 \cdot 87$. It should be noted that $M_{\mathrm{s}}$ for liquefied soils obtained from the finite-element analysis carried out in this study was lower than that derived by Klar (2008) for a perfectly plastic material $\left(M_{\mathrm{s}}=2 \cdot 6\right)$.

\section{VALIDATION OF PROPOSED $p-y$ CURVES FOR LIQUEFIABLE SOILS}

To validate the proposed $p-y$ curve for liquefied soils, a series of centrifuge tests were re-analysed in order to backcalculate $p-y$ curves from available experimental data. The tests considered in this paper were carried out in the centrifuge facility of Shimizu Corporation (Japan). Detailed information of the centrifuge facility can be found in Sato (1994).
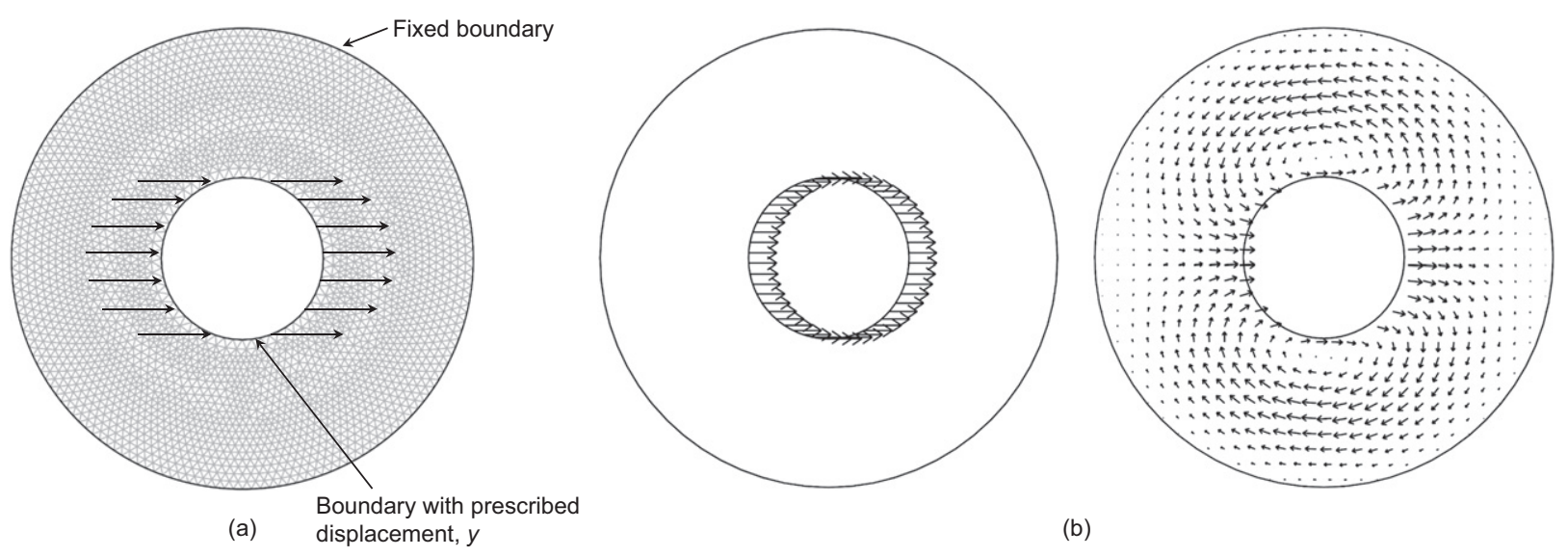

(b)

Fig. 10. Numerical model used for evaluation of scaling factors $M_{\mathrm{s}}$ and $N_{\mathrm{s}}$ : (a) mesh used in FE model; (b) boundary value problem - left; deformation mechanism - right 


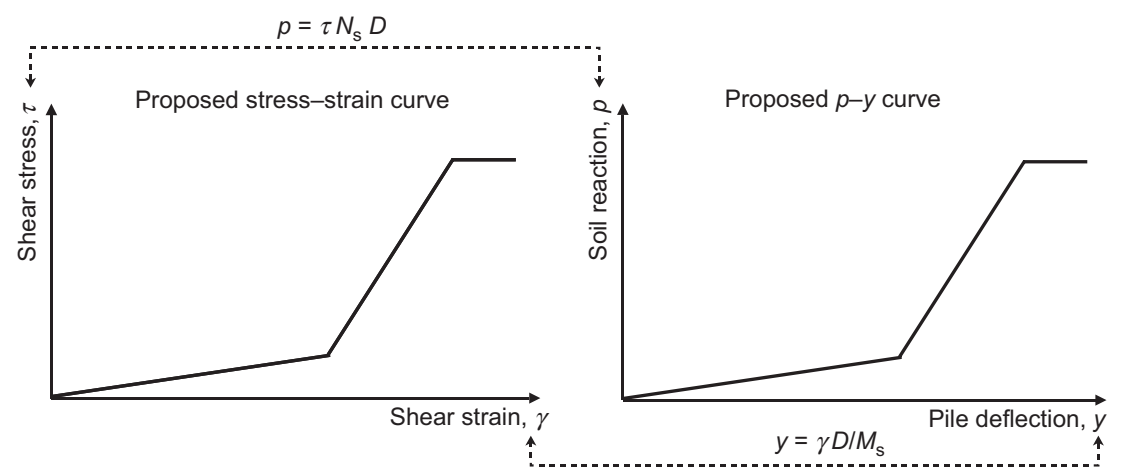

(a)

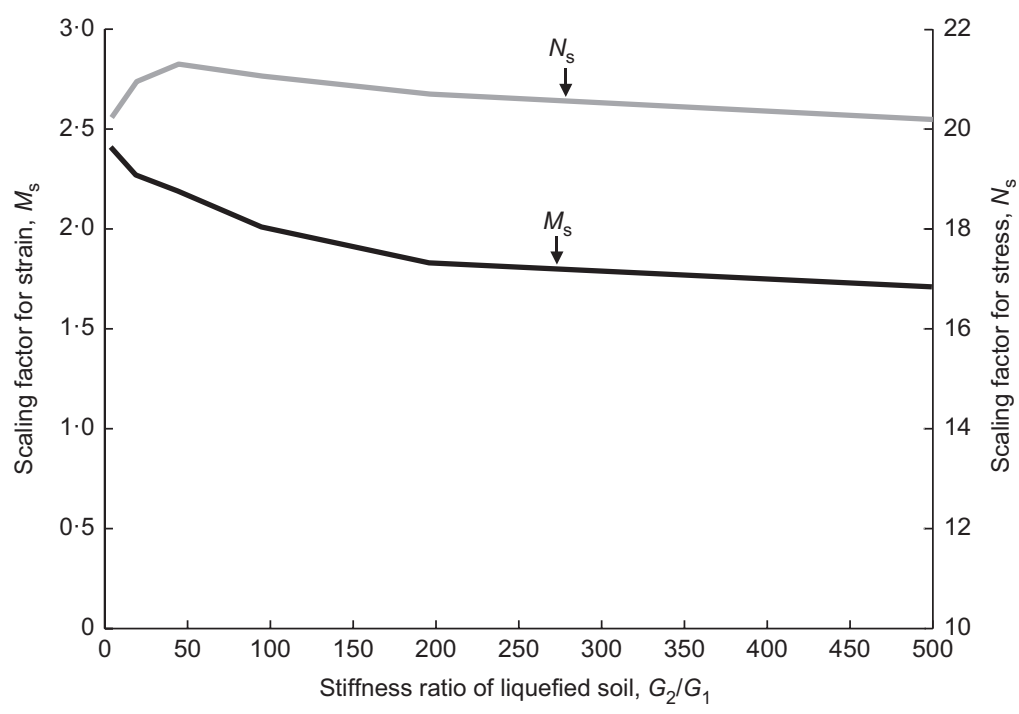

(b)

Fig. 11. (a) Proposed scaling approach for derivation of $p-y$ curves from stress-strain curve. (b) Computed scaling factors $M_{\mathrm{s}}$ and $N_{\mathrm{s}}$ for different stiffness ratios $G_{2} / G_{1}$

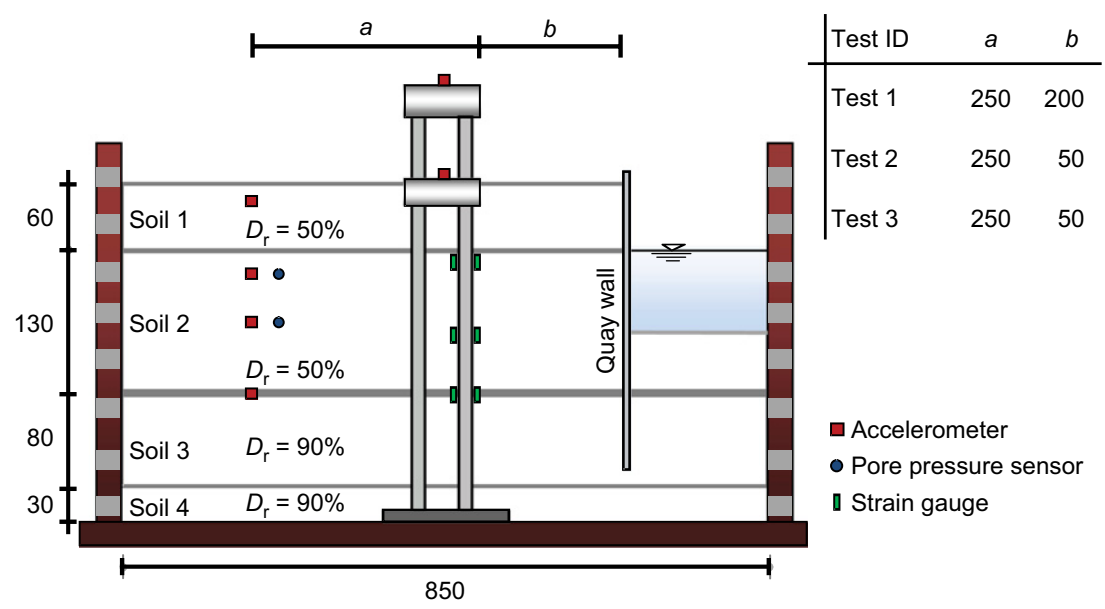

Fig. 12. Test set-up and instrumental layout used in centrifuge tests (dimensions, mm)

\section{Centrifuge tests}

The tests were performed at a centrifugal acceleration of $30 \mathrm{~g}$. The model container consisted of a laminar box, with inner dimensions of $805 \mathrm{~mm}$ long, $475 \mathrm{~mm}$ wide and $324 \mathrm{~mm}$ deep. The soil deposit comprised four soil layers, prepared at different densities and using different sands, namely silica sand and Toyoura sand. The thickness and relative density of each layer are specified in Fig. 12. To restrict the occurrence of liquefaction to soil layer 2 , layer 1 was unsaturated (i.e. degree of saturation of $10 \%$ ), whereas layers 3 and 4 were prepared at higher densities $\left(D_{\mathrm{r}}=90 \%\right)$. A summary of the scaling parameters used for the construction of the models and interpretation of experimental results is given in Table 3. Derivations of these parameters can be found in Schofield (1981). It is noted that to satisfy the scaling requirement for the diffusion process, a high-viscosity silicone oil of $30 \mathrm{cS}$ was used as the pore fluid.

A schematic diagram of the instrumentation layout is given in Fig. 12. The physical model consisted of a $2 \times 2$ pile group 
made of steel pipes. Each pile had an outer diameter of $10 \mathrm{~mm}$, wall thickness of $0.2 \mathrm{~mm}$ and total length of $270 \mathrm{~mm}$. Pile ends were fully fixed to a rigid plate fitted onto the base of the model container. One pile in each configuration was instrumented with pairs of strain gauges. The model included a rigid quay wall located in front of the pile group, but this is not considered in the present study. Other transducers included pore pressure sensors, accelerometers and displacement transducers. In the present study, three tests were considered for the back-calculation of $p-y$ curves. Each test was carried out under nearly identical conditions in terms of input motion and relative density of the liquefiable layer. However, different distances between quay wall and piled structure were used in each test, as specified in Fig. 12. The input motion consisted of a sine wave with a constant frequency of $60 \mathrm{~Hz}$, which corresponded to a forcing frequency of $2 \mathrm{~Hz}$ at prototype scale. The amplitude of the sine wave was gradually incremented, attaining a value of $8 g$ (i.e. $0 \cdot 27 g$ at prototype scale) after approximately $0.25 \mathrm{~s}$. In the three tests, the onset of liquefaction occurred in 5-6 cycles of loading.

\section{Derivation of $\mathrm{p}-\mathrm{y}$ curves from test data}

The derivation of the $p-y$ curves involved three major steps.

(a) Double integration of soil acceleration to compute soil displacement, $y_{\mathrm{s}}$.

Table 3. Scaling laws for centrifuge modelling

\begin{tabular}{l|l|l}
\hline Quantity & Dimension & Model/prototype \\
\hline Stress & $(M / L) / T^{2}$ & 1 \\
Strain & - & 1 \\
Length & $L$ & $1 / n$ \\
Time (dynamic) & $T$ & $1 / n$ \\
Acceleration & $L / T^{2}$ & $n$ \\
Frequency & $T^{-1}$ & $n$ \\
Diffusion time & $T$ & $1 / n^{2}$ \\
\hline
\end{tabular}

(b) Double integration of bending moment along the pile to obtain pile deflection, $y_{\mathrm{p}}$. The relative pile-soil displacement $y$ was subsequently computed as the difference $y_{\mathrm{p}}-y_{\mathrm{s}}$;

(c) Double differentiation of bending moment along the pile to obtain soil reaction, $p$.

As the numerical operations of integration and differentiation are sensitive to low-frequency and high-frequency noise, a band-pass Butterworth filter was applied to all records before signal processing. Furthermore, because the computed bending moments were known only at discrete locations, a cubic spline interpolation function was used to obtain a continuous bending curve along the instrumented pile. A similar interpolation function was successfully employed by Wilson (1998) and Jeanjean (2009) for the evaluation of $p-y$ curves. The back-calculated $p-y$ curves are illustrated in Fig. 13, in which the soil resistance $p$ is normalised by the effective stress, $\sigma_{\mathrm{v}}^{\prime}$, and pile diameter, $D$; and the displacement, $y$, is normalised by the pile diameter, $D$. Based on the back-calculated $p-y$ curves, the following conclusions may be drawn.

(a) Figure 13 displays $p-y$ curves relative to three depths within the liquefiable layer (i.e. soil layer 2 in Fig. 12). It can be seen that the back-calculated $p-y$ curves exhibited practically zero stiffness at small deflection. Evidently, these exhibit a different shape from the $p-y$ curves used in routine practice, such as the ones obtained from the $p$-multiplier method illustrated in Fig. 1, which significantly overestimate the stiffness of the foundation, particularly at small displacements. The implication of using $p-y$ curves having different shapes has been previously discussed through the schematic representation in Fig. 3(a).

(b) Figure 14 compares the back-calculated $p-y$ curves with those computed from the proposed and $p$-multiplier methods. It can be observed that the back-calculated $p-y$ curves exhibit low stiffness at small lateral displacement, and increasing stiffness and lateral
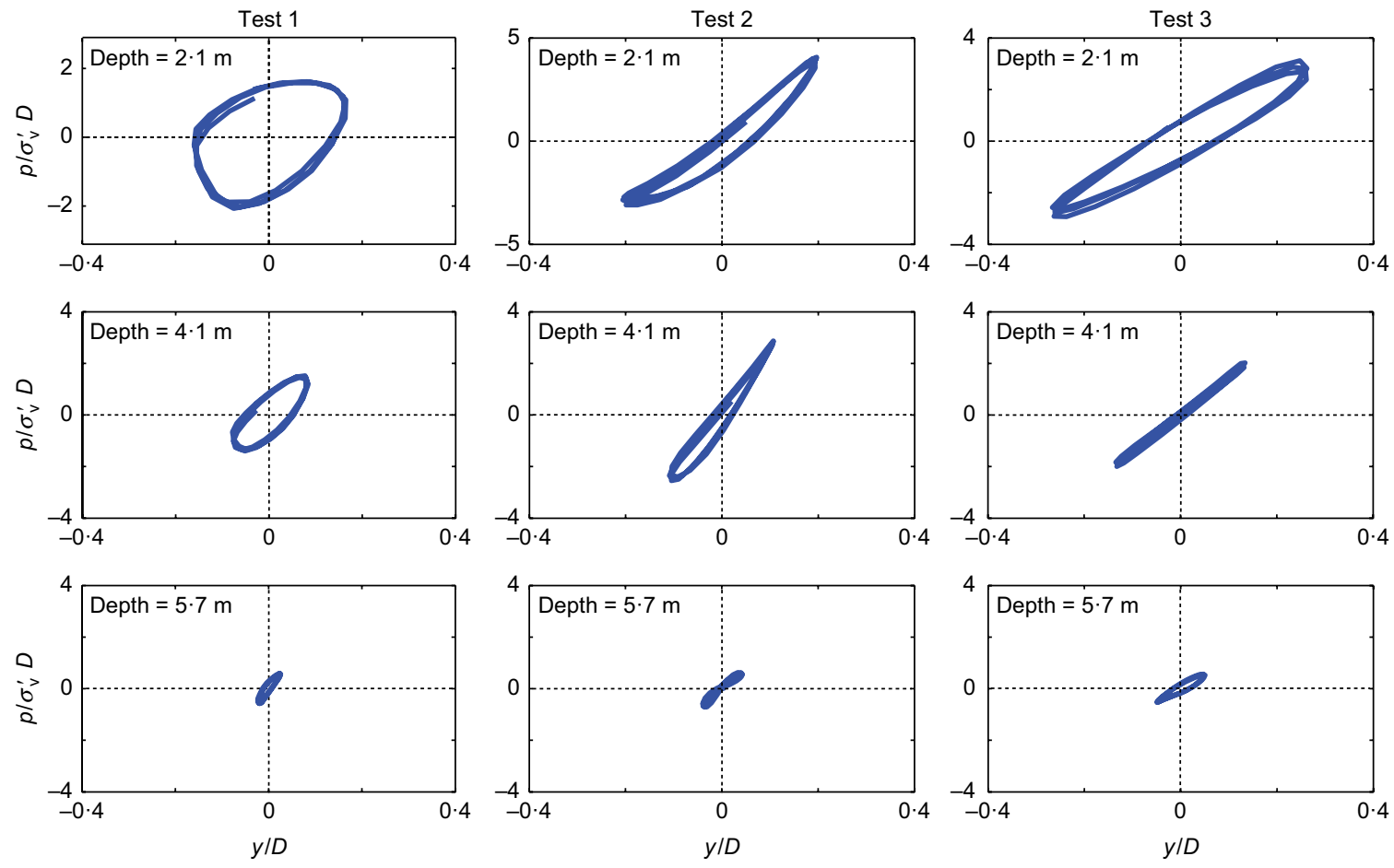

Fig. 13. Back-calculated $p-y$ curves from centrifuge tests 


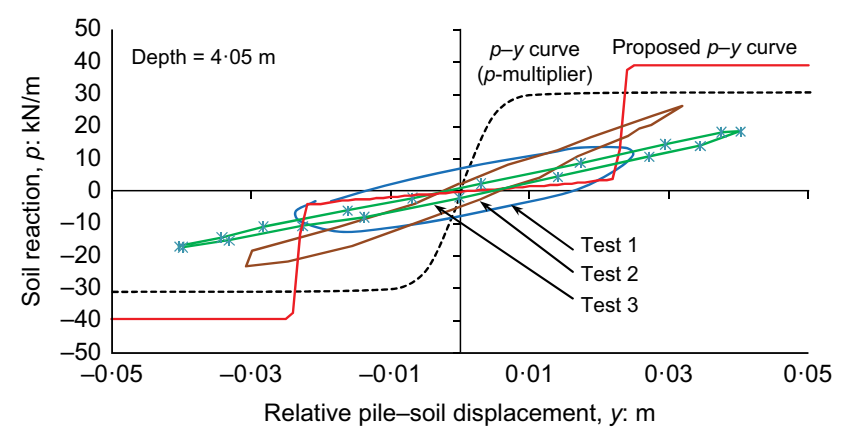

Fig. 14. Comparison between $p-y$ curves back-calculated from centrifuge tests and $p-y$ curves constructed according to proposed method and $p$-multiplier approach

resistance with increasing $y$. This strain-hardening behaviour is better captured by the proposed $p-y$ curves rather than the routine method, which clearly overestimate the initial foundation stiffness.

\section{CONCLUSIONS}

The paper proposes a simplified $p-y$ curve construction procedure for the analysis of soil-pile interaction problems in liquefiable soils. The procedure requires the stress-strain of the liquefied soil, and appropriate scaling factors for the conversion of stress-strain into compatible soil resistance $p$ and soil-pile relative deflection $y$. In contrast to existing $p-y$ curves for liquefiable soils, the proposed curves retain the essential features of liquefied soil as observed in both element and physical model tests. These include practically zero strength and stiffness at low strains (i.e. $\gamma<\gamma_{\text {to }}$ ); and strain-hardening behaviour at large strains.

Compared with the $p$-multiplier method, the proposed $p-y$ curves are more consistent with those back-calculated from a series of centrifuge tests analysed in this study. On the other hand, the proposed method underestimates the pile displacement upon which the soil regains strength and stiffness, resulting in a sharp increase in stiffness at medium to large displacement levels.

Despite the simplicity of the method, the proposed $p-y$ curves can conveniently be implemented in routine practice for use in design and decision making.

All research data accompanying this publication are available at http://dx.doi.org/10.15127/1.305161 (Lombardi, 2016).

\section{ACKNOWLEDGEMENTS}

The work is partially funded by the EPSRC (Engineering and Physical Sciences Research Council, UK) through the grant EP/H015345/2. The first author would like to acknowledge the funding received through University of Bristol Centenary PhD Scholarship for 3 years. The third author would also like to acknowledge University of Bristol for the University Senior Research Fellowship for the year 2011 to 2012. The second author would like to acknowledge the financial help received from UK-India Education Research Initiative (UKIERI) towards his DPhil study at the University of Oxford (2007-2011), supporting part of the work presented in this paper.

\section{NOTATION}

$D$ diameter of the pile

$D_{\text {r }}$ relative density

$D_{50}$ particle size corresponding to $50 \%$ passing
$E$ void ratio

$\dot{E}$ dissipation of energy within deforming soil

$e$ initial void ratio

$e_{\max }$ maximum void ratio

$e_{\min }$ minimum void ratio

$G_{\max }$ maximum shear modulus

$G_{\mathrm{s}} \quad$ specific gravity

$G_{1} \quad$ initial shear modulus

$G_{2}$ shear modulus at large strains

$k$ modulus of subgrade reaction

$M_{\mathrm{c}}$ stress ratio at critical state

$M_{\mathrm{s}}$ scaling factor for strain

$m_{\mathrm{p}} \quad$ reduction factor for $p-y$ curves for liquefied soils

$N_{\text {s }} \quad$ scaling factor for stress

$\left(N_{1}\right)_{60}$ equivalent clean sand blow count from SPT

$n$ scaling factor

$p$ soil reaction

$p_{\mathrm{a}}$ atmospheric pressure

$p_{\mathrm{u}}$ ultimate soil reaction

$q$ deviator stress

$R$ radius of deformable soil

$r_{\mathrm{u}}$ excess pore water pressure ratio

$r_{0}$ outer radius

$S_{\mathrm{r}} \quad$ residual strength of liquefied soil

$U_{\mathrm{c}}$ coefficient of uniformity

$V$ volume

$\dot{W} \quad$ work done by external load

$y$ pile-soil deflection

$y_{\mathrm{p}}$ pile deflection

$y_{\mathrm{s}}$ soil deflection

$z$ depth below ground surface

$\gamma_{\text {mob }}$ mobilised shear strain

$\gamma_{\mathrm{s}}$ engineering shear strain

$\gamma_{\text {to }}$ take-off strain

$\varepsilon_{\mathrm{a}}$ axial strain

$\varepsilon_{\mathrm{r}} \quad$ radial strain

$\varepsilon_{1} \quad$ major principal strain

$\varepsilon_{2} \quad$ minor principal strain

$\sigma_{\mathrm{a}}$ axial stress

$\sigma_{\mathrm{c}}^{\prime} \quad$ effective confining stress

$\sigma_{\mathrm{r}}$ radial stress

$\sigma_{\theta}$ circumferential (or tangential) stress

$\sigma_{1}$ major principal stress

$\sigma_{3}$ minor principal stress

$\tau$ shear stress

$\tau_{\max }$ maximum shear stress

$\tau_{\text {mob }}$ mobilised shear stress

$\tau_{\mathrm{r} \theta}$ radial shear stress

\section{REFERENCES}

AIJ (Architectural Institute of Japan) (2001). Recommendations for design of building foundations. Tokyo, Japan: Architectural Institute of Japan.

API (American Petroleum Institute) (2000). Recommended practice for planning, designing, and constructing fixed onshore platforms - working stress design, RP 2A-WSD, 21st edn. Washington, DC, USA: American Petroleum Institute.

Ashford, S. A. \& Rollins, K. M. (2002). TILT: 'The Treasure Island liquefaction test', Final Report No. SSRP 2001/17. San Diego, CA, USA: Department of Structural Engineering, University of California.

Bhattacharya, S. (2003). Pile instability during earthquake liquefaction. PhD thesis, University of Cambridge, Cambridge, UK.

Bhattacharya, S., Madabhushi, S. P. G. \& Bolton, M. D. (2004). An alternative mechanism of pile failure in liquefiable deposits during earthquakes. Géotechnique 54, No. 3, 203-213, http://dx. doi.org/10.1680/geot.2004.54.3.203.

Bhattacharya, S., Bolton, M. D. \& Madabhushi, S. P. G. (2005a). A reconsideration of the safety of the existing piled bridge foundations in liquefiable soils. Soils Found. 45, No. 4, 13-26.

Bhattacharya, S., Madabhushi, S. P. G. \& Bolton, M. D. (2005b). Discussion: an alternative mechanism of pile failure in liquefiable deposits during earthquakes. Géotechnique 55, No. 3, 259-263, http://dx.doi.org/10.1680/geot.2005.55.3.259. 
Bolton, M. D. \& Powrie, W. (1988). Behaviour of diaphragm walls in clay prior to collapse. Géotechnique 38, No. 2, 167-189, http://dx.doi.org/10.1680/geot.1988.38.2.167.

Boulanger, R. W., Kutter, B. L., Brandenberg, S. J., Singh, P. \& Chang, D. (2003). Pile foundations in liquefied and laterally spreading ground during earthquakes: centrifuge experiments and analyses, No. UCD/CGM-03/01. Davis, CA, USA: Center for Geotechnical Modeling, Department of Civil and Environmental Engineering, University of California.

Bouzid, D. J., Bhattacharya, S. \& Dash, S. R. (2013). Winkler Springs ( $p-y$ curves) for pile design from stress-strain of soils: FE assessment of scaling coefficients using the mobilized strength design concept. Geomech. Engng 5, No. 5, 379-399.

Brandenberg, S. J. (2005). Behaviour of pile foundations in liquefied and laterally spreading ground. $\mathrm{PhD}$ thesis, University of California, Davis, CA, USA.

Comsol (2009). COMSOL multyphysics user guide, Version 3-5a. Stockholm, Sweden: Comsol.

Cubrinovski, M. \& Bradley, B. (2008). Assessment of seismic performance of soil-structure systems. Proceedings of the 18th New Zealand Geotechnical Society 2008 symposium, Auckland, New Zealand, pp. 111-127.

Cubrinovski, M., Kokusho, T. \& Ishihara, K. (2006). Interpretation from large scale shake table tests on piles undergoing lateral spreading in liquefied soils. Soil Dynam. Earthquake Engng 26, No. 2, 275-286.

Dash, S. (2010). Lateral pile-soil interaction in liquefiable soils. PhD thesis, University of Oxford, Oxford, UK.

Dash, S. R., Bhattacharya, S. \& Blakeborough, A. (2010). Bending-buckling interaction as a failure mechanism of piles in liquefiable soils. Soil Dynam. Earthquake Engng 30, No. 1-2, 32-39.

Dobry, R., Taboada, V. \& Liu, L. (1995). Centrifuge modeling of liquefaction effects during earthquakes. Proceedings of the $1 \mathrm{st}$ international conference on earthquake geotechnical engineering, Tokyo, Japan, pp. 14-16.

Goh, S. \& O'Rourke, T. D. (1999). Limit state model for soil-pile interaction during lateral spread. Proceedings of the 7 th US-Japan workshop on earthquake resistant design of lifeline facilities and countermeasures against soil liquefaction, Seattle, WA, USA, pp. 237-260.

Haigh, S. K. (2002). Effects of liquefaction on pile foundations in sloping ground. $\mathrm{PhD}$ thesis, University of Cambridge, Cambridge, UK.

Hetényi, M. (1946). Beams on elastic foundation. Theory with applications in the fields of civil and mechanical engineering. Ann Arbor, MI, USA: The University of Michigan Press.

Ishibashi, I. \& Zhang, X. (1993). Unified dynamic shear moduli and damping ratios of sand and clay. Soils Found. 33, No. 1, 182-191.

Ishihara, K. (1995). Soil behaviour in earthquake geotechnics. Oxford, UK: Oxford Science Publications.

Jeanjean, P. (2009). Re-assessment of $p-y$ curves for soft clays from centrifuge testing and finite element modeling. Proceedings of the offshore technology conference, Houston, TX, USA, paper OTC 20158.

Kiku, H. \& Tsujino, S. (1996). Post liquefaction characteristics of sand. Proceedings 11th world conference on earthquake engineering, Acapulco, Mexico, Paper No. 1088.

Klar, A. (2008). Upper bound for cylinder movement using 'Elastic' fields and its possible application to pile deformation analysis. Int. J. Geomech. 8, No. 2, 162-167.

Klar, A. \& Osman, A. S. (2008). Load-displacement solutions for piles and shallow foundations based on deformation fields and energy conservation. Géotechnique 58, No. 7, 581-590, http://dx.doi.org/10.1680/geot.2008.58.7.581.

Knappett, J. A. \& Madabhushi, S. P. G. (2009). Influence of axial load on lateral pile response in liquefiable soils. Part II: numerical modelling. Géotechnique 59, No. 7, 583-592, http://dx.doi.org/10.1680/geot.8.010.3750.

Kokusho, T., Hara, T. \& Hiraoka, R. (2004). Undrained shear strength of granular soils with different particle gradations. J. Geotech. Geoenviron. Engng 130, No. 6, 621-629.

Kramer, S. L. (1996). Geotechnical earthquake engineering (vol. 80). Upper Saddle River, NJ, USA: Prentice Hall.
Lombardi, D. (2013). Dynamics of pile-supported structures in seismically liquefiable soils. PhD thesis, University of Bristol, Bristol, UK.

Lombardi, D. (2016). Experimental data used in the manuscript entitled "Construction of simplified design $p-y$ curves for liquefied soil" by Lombardi et al (2017). Manchester, UK: The University of Manchester. See http://dx.doi.org/10.15127/1. 305161 (accessed 19/10/2016).

Lombardi, D. \& Bhattacharya, S. (2014a). Liquefaction of soil in the Emilia-Romagna region after the 2012 Northern Italy earthquake sequence. Natural Hazards 73, No. 3, 1749-1770.

Lombardi, D. \& Bhattacharya, S. (2014b). Modal analysis of pile-supported structures during seismic liquefaction. Earthquake Engng Struct. Dynam. 43, No. 1, 119-138.

Lombardi, D. \& Bhattacharya, S. (2016). Evaluation of seismic performance of pile-supported models in liquefiable soils. Earthquake Engng Struct. Dynam. 45, No. 6, 1019-1038.

Lombardi, D., Bhattacharya, S., Hyodo, M. \& Kaneko, T. (2014). Undrained behaviour of two silica sands and practical implications for modelling SSI in liquefiable soils. Soil Dynam. Earthquake Engng 66, 293-304.

Madabhushi, S. P. G., Knappett, J. A. \& Haigh, S. K. (2010). Design of pile foundations in liquefiable soils. London, UK: Imperial College Press.

Martin, C. M. \& Randolph, M. F. (2006). Upper-bound analysis of lateral pile capacity in cohesive soil. Géotechnique 56, No. 2, 141-145, http://dx.doi.org/10.1680/geot.2006.56.2.141.

Matlock, H. (1970). Correlation for design of laterally loaded piles in soft clay. Proceedings of the offshore technology conference, Houston, TX, USA, paper OTC 1204.

Olson, S. M. \& Stark, T. D. (2002). Liquefied strength ratio from liquefaction flow failure case histories. Can. Geotech. J. 39, No. 3, 629-747.

O’Neill, M. W. \& Murchison, J. M. (1983). An evaluation of $p-y$ relationships in sands, Report to the American Petroleum Institute. Austin, TX, USA: University of Texas.

Osman, A. S. \& Bolton, M. D. (2004). A new design method for retaining walls in clay. Can. Geotech. J. 41, No. 3, 451-466.

Osman, A. S. \& Bolton, M. D. (2005). Simple plasticity-based prediction of the undrained settlement of shallow circular foundations on clay. Géotechnique 55, No. 6, 435-447, http://dx.doi.org/10.1680/geot.2005.55.6.435.

Pillai, V. S. \& Salgado, F. M. (1994). Post-liquefaction stability and deformation analysis of Duncan Dam. Can. Geotech. J. 31, No. 6, 967-978.

Randolph, M. F. \& Houlsby, G. T. (1984). The limiting pressure on a circular pile loaded laterally in cohesive soil. Géotechnique 34, No. 4, 613-623, http://dx.doi.org/10.1680/geot.1984.34. 4.613.

Reese, L., Cox, W. \& Koop, F. (1974). Analysis of laterally loaded piles in sand. Proceedings of the offshore technology conference, Houston, TX, USA, paper OTC 2080.

Reese, L., Cox, W. \& Koop, F. (1975). Field testing and analysis of laterally loaded piles in stiff clay. Proceedings of the offshore technology conference, Houston, TX, USA, paper OTC 2312.

Sato, M. (1994). A new dynamic geotechnical centrifuge and performance of shaking table tests. In Centrifuge 94 (eds F. H. Lee, C. F. Leung and T. S. Tan), pp. 157-162. Rotterdam, the Netherlands: Balkema.

Schofield, A. N. (1981). Dynamic and earthquake geotechnical centrifuge modelling. Proceedings of the international conference on recent advances in geotechnical earthquake engineering and soil dynamics, Rolla, MO, USA, vol. 3, pp. 1081-1110.

Seed, H. B. (1979). Considerations in the earthquake-resistant design of earth and rockfill dams. Géotechnique 29, No. 3, 215-263, http://dx.doi.org/10.1680/geot.1979.29.3.215.

Seed, R. B. \& Harder, L. F. Jr (1990). SPT-based analysis of cyclic pore pressure generation and undrained residual strength. In Proceedings of the H.B.Seed memorial symposium (ed. J. M. Duncan), vol. 2, pp. 351-391. Vancouver, BC, Canada: Bi-Tech Publishing Ltd.

Sitharam, T. G., Vinod, J. S. \& Ravishankar, B. R. (2009). Post-liquefaction undrained monotonic behaviour of sands: experiments and DEM simulations. Géotechnique 59, No. 9, 739-749, http://dx.doi.org/10.1680/geot.7.00040. 
Sivathayalan, S. (1994). Static cyclic and post liquefaction simple shear response of sands. MSc thesis, University of British Columbia, Vancouver, BC, Canada.

Sivathayalan, S. \& Vaid, Y. P. (2004). Cyclic resistance and post liquefaction response of undisturbed in-situ sands. Proceedings of the 13th world conference on earthquake engineering, Vancouver, BC, Canada, Paper No. 2940.

Stringer, M. E. \& Madabhushi, S. P. G. (2012). Axial load transfer in liquefiable soils for free-standing piles. Géotechnique 63, No. 5, 400-4009, http://dx.doi.org/10.1680/geot.11.P.078.

Thomas, J. (1992). Static, cyclic and post liquefaction undrained behaviour of Fraser River sand. MSc thesis, University of British Columbia, Vancouver, BC, Canada.

Tokimatsu, K., Suzuki, H. \& Suzuki, Y. (2001). Back-calculated $p-y$ relation of liquefied soils from large shaking table tests. Proceedings of the 4th international conference on recent advances in geotechnical earthquake engineering and soil dynamics (ed. S. Prakash). Paper No. 6.24, Rolla, MO, USA: University of Missouri-Rolla.

Vaid, Y. P. \& Thomas, J. (1995). Liquefaction and post liquefaction behavior of sand. J. Geotech.Engng 121, No. 2, $163-173$.

Vardanega, P. J. \& Bolton, M. D. (2011). Strength mobilization in clays and silts. Can. Geotech. J. 48, No. 10, 1485-1503.
Wilson, D. W. (1998). Soil-pile-superstructure interaction in liquefying sand and soft clay. $\mathrm{PhD}$ thesis, University of California, Davis, CA, USA.

Wilson, D. W., Boulanger, R. W. \& Kutter, B. L. (2000). Observed seismic lateral resistance of liquefying sand. J. Geotech. Geoenviron. Engng 126, No. 10, 898-906.

Winkler, E. (1867). Die Lehre von der Elasticitaet und Festigkeit. Prague: Dominicus, (in German).

Yasuda, S., Masuda, T., Yoshida, N., Nagase, H., Kiku, H., Itafuji, S., Mine, K. \& Sato, K. (1994). Torsional shear and triaxial compression tests on deformation characters of sands before and after liquefaction. Proceedings of the 5th US-Japan workshop on earthquake resistant design of lifelines and countermeasures against soil liquefaction, Salt Lake City, UT, USA, pp. 249-265.

Yasuda, S., Terauchi, T., Morimoto, M., Erken, A. \& Yoshida, N. (1998). Post liquefaction behavior of several sands. In Proceedings of the 11th European conference on earthquake engineering (eds P. Bisch, P. Labbe and A. Pecker). Rotterdam, the Netherlands: Balkema (CD-ROM).

Yoshida, N., Yasuda, S., Kiku, M., Masuda, T. \& Finn, W. D. L. (1994). Behaviour of sand after liquefaction. Proceedings of the US-Japan workshop on earthquake resistant design of lifeline facilities and countermeasures against soil liquefaction, Buffalo, NY, USA, vol. 5, pp. 181-198. 